Diego García-Peinazo

Universidad de Córdoba

Julio Ogas

Universidad de Oviedo

\title{
Introducción. De entramados sonoros y descubrimientos
}

\section{Introduction. Frameworks of Sound and Discoveries}

Andrés andaba buscando explicaciones de algo que se le escapaba en la audición de Prozession [...] pasó un buen rato antes de que se diera cuenta de que la cosa estaba en el piano. Entonces es así [...] entre los sonidos electrónicos o tradicionales pero modificados por el empleo que hace Stockhausen de filtros y micrófonos, de cuando en cuando se oye con claridad, con su sonido propio, el piano. Tan sencillo en el fondo: el hombre viejo y el hombre nuevo en este mismo hombre sentado estratégicamente para cerrar el triángulo de la estereofonía [...] en mitad de un complejo sonoro donde todo es descubrimiento asoman como fotos antiguas su color y su timbre, [...] el piano me suena como un reconocimiento que concentra la atención, me despierta más agudamente a algo que todavía sigue atado a mí por ese instrumento que hace de puente entre pasado y futuro.

Este fragmento del Libro de Manuel ${ }^{1}$ de Julio Cortázar expresa el núcleo de ese proceso dual de mostrar y descubrir qué se establece entre el compositor y el oyente (o viceversa) cuando una obra incluye en su forma elementos relacionados con un repertorio anterior. El pasaje del libro donde Andrés realiza su "descubrimiento" (del cual hemos extraído este fragmento) expone el proceso reflexivo de este personaje, presentando la causa (el sonido del piano) que genera su inquietud inicial y su razonamiento posterior, a la vez que interpela al lector sobre los posibles motivos del compositor para incluir ese sonido y la adecuación de las competencias de ese oyente para interpretarlas. Este espacio literario, donde se superponen y confunden las contradicciones internas del protagonista y las que (según él) contiene la composición musical sobre la que reflexiona, se inserta en una trama habitada por diferentes apariencias de la contradicción entre lo nuevo y lo viejo. Apariencias impregnadas por las posturas ideológicas, vitales y estéticas de sus personajes, y descritas por el autor a partir de la combinación del relato novelado con

${ }^{1}$ Julio Cortázar: Libro de Manuel, Barcelona, Edhasa, 1973, pp. 25-26. 
recortes periodísticos que cita a la manera de collage (anticipándose, de esta forma, al uso de los enlaces web -links-) que permiten el salto de un hipertexto a otro $)^{2}$.

Recursos como los empleados por Cortázar en esta obra, que algunos autores asocian con el pastiche posmoderno jamesiano ${ }^{3}$, aparecen con frecuencia en la literatura y el arte a lo largo de la historia. Sin embargo, es posible decir que en los años en los que se publica este libro adquiere especial relevancia un modo de hacer artístico y literario por el cual los autores recurren a cierta red de significados a partir de establecer una relación tangible entre su creación textual y textos precedentes. Aspecto que está directamente ligado con la idea de un receptor activo, que pone en juego su propia red textual para aportar un sentido personal a la obra. Esto, como es sabido, da origen, en la última parte del siglo XX, a un número importante de estudios sobre literatura, arte y música que, en cierta forma, sientan las bases para el desarrollo del estudio de las relaciones textuales en las últimas décadas.

Esta conjunción de coordenadas temporales y de estructuración del discurso constituye el primer punto de referencia por el cual recurrimos a ese pasaje del escritor argentino como inicio de este dosier sobre hiper/intertextualidad musical. Por una parte, esos estudios surgidos entre los años setenta y ochenta del siglo pasado a los que hacíamos referencia, como pueden ser los de Julia Kristeva, Gerard Genette o Robert Hatten entre muchos otros, siguen siendo una fuente interesante de debates y revisiones que aparecen, explícita o implícitamente, en los trabajos de este volumen. Por otra parte, esa red de conexiones que "descubre" Andrés nos pone frente a un punto neurálgico del estudio musical para quienes, como los autores de este volumen, nos dedicamos al análisis de obras que tienen su germen compositivo ligado a una red textual de significados. Desde el punto de la musicología, Michael J. Puri expone un caso semejante al que describe Cortázar cuando explica su "descubrimiento" en una obra de Ravel.

En mi percepción se originó la idea de que había algo extraño -a la vez familiar y extraño- en la "Passacaille" del Trío con piano de Ravel. Finalmente, me di cuenta de que estaba escuchando elementos del Parsifal de Wagner (1877-1882), particularmente la progresión armónica distintiva que sustenta el Heilandsklage y que impregna la "Marcha al castillo del Grial" del primer acto. La progresión me había sonado extraña en la "Passacaille" porque inconscientemente había interna-

${ }^{2}$ Marisa Martínez Pérsico: "Los 'juglares electrónicos’ y la novísima narrativa hispanoamericana”, Caracteres. Estudios culturales y críticos de la esfera digital, 2, 1, mayo 2013, pp. 48-66.

${ }^{3}$ Alicia Mercado-Harvey: "Cortázar ganó por nocaut", Revista Surco Sur, 3, pp. 32-37. DOI: http://dx. doi.org/10.5038/2157-5231.3.5.15 (https://scholarcommons. usf.edu/surcosur/vol3/iss5/17, consulta 227-2019). 
lizado la idea de que, en contraste con la música de la generación anterior de compositores franceses (Chausson, d’Indy, Debussy, et al.), la música de Ravel no contenía wagnerismos ${ }^{4}$.

En definitiva, son estos puentes los que conducen al analista musical a un trabajo en el que, a partir del estudio de las relaciones entre el texto examinado y los precedentes para demostrar fehacientemente los diferentes puntos y formas de conexión, pone en juego sus competencias músico-culturales con el fin de exponer una interpretación del hecho artístico-musical. Interpretación que, a su vez, constituirá un nuevo eslabón para el lector a la hora de establecer sus propias relaciones de significados.

El otro punto de referencia del Libro de Manuel para esta publicación es la presencia de la otredad, tópico central de la escritura cortazariana. Otredad que el autor construye a partir de "delicados contactos [o] de maravillosos ajustes" entre la mano tendida desde dentro y la que responde desde fuera, "desde lo otro" 5 , donde lo ideológico, el lenguaje, la literatura, la traducción y la interpretación; la música de vanguardia y la música revolucionaria; o el exilio y la migración latinoamericana, entre otros aspectos, son protagonistas. Esos contactos y ajustes, producto de la confrontación con "el otro" y su cultura, están presentes también en los análisis desde la perspectiva de la hiper/intertextualidad de la música española y latinoamericana de los siglos XX y XXI que aquí se presentan. El estudio del discurso sonoro desde este enfoque permite ahondar en las formas que adoptan los procesos de recuperación, asimilación o apropiación de otras músicas por parte de grupos musicales y compositores de este ámbito músico-cultural. Procesos que, tanto en su expresión académica como popular urbana, adquieren especial interés dentro de este espacio fuertemente marcado por el sentido de otredad respecto a la música centroeuropea, la anglosajona y la tradicional de cada región. Una parte importante de la música iberoamericana es la "otra" frente a la centroeuropea y estadounidense, ante las cuales debe mimetizarse o destacar su singularidad, al tiempo que lo es también respecto a las músicas tradicionales/locales a las que trata de imitar, elevar culturalmente o abducir estéticamente. El análisis de los espacios

\footnotetext{
4 "It originated in my perception that there was something uncanny-simultaneously familiar and strange_about the 'Passacaille' movement from Ravel's Piano Trio. Eventually I realized I was hearing elements of Wagner's Parsifal (1877-82), particularly the distinctive harmonic progression that underpins the Heilandsklage and pervades Act I's 'March to the Castle of the Grail'. The progression had sounded strange to me in the 'Passacaille' because I had unwittingly internalized the received wisdom that, in contrast to the music of the previous generation of French composers (Chausson, d'Indy, Debussy, et al.), Ravel's music contained no Wagnerisms". Michael J. Puri: "Ravel's Valses nobles et sentimentales and its Models", Music Theory Online, 23, 3, septiembre 2017, p. 2 (http://www.mtosmt.org/issues/mto.17.23.3/ mto.17.23.3.puri.php, consulta 20-8-2019).

${ }^{5}$ Julio Cortázar: Rayuela, La Habana, Casa de Las Américas, 2004, p. 111.
} 
hiper/intertextuales presente en las creaciones musicales de diferentes músicos populares y académicos iberoamericanos, ya sea a través de la utilización y tratamiento de uno o varios fragmentos específicos de músicas precedentes o de la imitación estilística, nos acerca la forma en que estos autores buscan representar la vinculación de su trabajo con determinados valores músico-culturales de otras épocas o de otras latitudes. A su vez, estos vínculos constituyen indicios para el análisis de posibles relaciones de textos con construcciones identitarias puestas en marcha por determinados grupos socioculturales, relacionados con los músicos o con los ámbitos de recepción de su música.

Como se aprecia en los párrafos precedentes, el espacio que ocupa la interpretación en el análisis del entramado discursivo que proponen los compositores y grupos musicales, al recurrir deliberadamente a textos preexistentes, constituye el punto de convergencia para este dosier. Por ello, entendemos necesaria la concurrencia de puntos de vistas que tengan como referencia tanto la línea de la intertextualidad fundada por Julia Kristeva como la de la hipertextualidad propuesta por Gérard Genette, así como de aquellos que en el campo musical han seguido, más o menos fielmente, uno u otro enfoque. Ambos campos teóricos ofrecen al análisis musicológico coordenadas lo suficientemente precisas y flexibles para abordar un estudio de la música iberoamericana que tenga en cuenta las relaciones entre el fenómeno sonoro y los espacios culturales donde se generan y consumen. Por ello, no solo nos interesa el puente entre lo viejo y lo nuevo que se establece entre ciertos productos musicales y otros que le precedieron, sino también tratamos de establecer esas conexiones entre diferentes espacios de nuestra disciplina y de otras, como parte de ese interés por el vínculo entre espacios sonoros y temporalidades culturales. Todo ello teniendo en cuenta que el analista debe asumir la responsabilidad de ofrecer una interpretación cultural del hecho artístico-musical, aunque sea evidente que cada uno de los receptores puede dar un sentido personal a cada obra.

Así, Cristián Guerra aborda la presencia del canto gregoriano en la obra del compositor chileno Alfonso Letelier Llona, de tal manera que establece una vinculación entre esta decisión y la necesidad del músico de manifestar su relación con la tradición musical euroccidental y su oposición al destierro del canto gregoriano en las prácticas litúrgicas. Para ello, recurre a un marco de análisis tripartito en el cual atiende a la poiesis y circulación, la recepción y el uso intertextual del canto gregoriano, conjugando de esta forma la conocida propuesta de Nattiez-Molino con la empleada por Luis Merino Montero y Julio Garrido Letelier para el estudio de la música sinfónica de los compositores chilenos. Por su parte, Daniel Moro aborda la producción de un compositor bastante más rupturista, el español Miguel Ángel Coria. Según el autor, este compositor adopta el uso intertextual como una forma de expresar su rechazo a una visión lineal de la historia y defender el carácter 
artesanal de la composición, adscribiéndose así a la preocupación posmoderna por el cisma establecido por las vanguardias históricas entre la cultura de las élites y la cultura de las masas. El análisis aquí está enfocado en la forma en que Coria recurre a las alusiones en lugar de a las citas directas para homenajear a compositores como Maurice Ravel o Manuel de Falla, dentro de su particular concepción estética e ideológica que Moro rastrea en las críticas musicales escritas por el compositor.

Los conjuntos musicales Les Luthiers y La Banda Elástica sirven a Juliana Guerrero para reflexionar sobre el concepto de intertextualidad desde una dimensión comunicativa. Atendiendo a sus diferentes concepciones, que incluyen lo aportado por trabajos musicológicos, Guerrero apuesta por un enfoque que contemple una pluralidad de elementos asociados al evento musical más allá del propio lenguaje musical, como son "los instrumentos, las herramientas lingüísticas y las performances", entre otros. El humor en Les Luthiers y la hibridación de géneros musicales en el caso de La Banda Elástica son analizados en su trabajo considerando la necesidad de atender no solo al prisma de la intertextualidad desde el punto de vista de la creación musical, sino también a lo que la autora denomina "imaginario cultural de la audiencia".

Por su parte, en "Elogio de la apropiación. Prácticas impuras, flamenco y creación contemporánea”, Pedro Ordóñez profundiza en la problemática de la pureza asociada a las prácticas flamencas desde la intertextualidad. Tomando como estudio de caso ejemplos de Niño de Elche o Mauricio Sotelo, entre otros, el autor emplea la apropiación musical como eje transversal para analizar las lógicas de la (im)pureza en músicas populares y académicas, conectando estas con la creación artística contemporánea. Para Ordóñez, lo impuro se presenta de manera plurifocal en diferentes artistas, pero entrelazados con una dimensión omnívora de lo cultural. Abordando préstamos de distinta naturaleza, su trabajo evidencia la necesidad de superar una visión negativa o peyorativa del concepto de apropiación en las músicas flamencas.

Del sampleo en el post-rock español se ocupa Ugo Fellone, quien analiza su uso tomando como punto de partida los estudios sobre transfonografia desarrollados por Serge Lacasse. El artículo traza la evolución del uso de este recurso hiper/intertextual -desde fragmentos de films hasta registros de campoen la etiqueta "post-rock" desde los años noventa del siglo XX hasta nuestros días, exponiendo las transformaciones presentes en la canción grabada de postrock desde el plano intrafonográfico e interfonográfico. Esto permite a Fellone conectar elementos sonoros con dinámicas histórico-culturales, y comprobar cómo la evolución del sample en el post-rock -un juego más entre lo viejo y lo nuevo- pasa de presentar "un régimen predominantemente lúdico y experimental a un uso más serio y artístico" de esta estrategia transfonográfica. 
En nuestros trabajos, Diego García-Peinazo aborda la supertónica descendida en la canción grabada de heavy metal español como un elemento central en los discursos intertextuales de este género musical. Esta estructura se erige como un signo musical ambivalente que funciona tanto como indicador estilístico del metal como representación de músicas vinculadas a la idea de lo andaluz, lo flamenco y lo árabe. En este sentido, García-Peinazo plantea un análisis que profundiza en la forma en que este elemento melódico-armónico dialoga de manera ambigua y contradictoria con algunas de las temáticas habituales del género, como la recurrencia a mitos históricos y héroes nacionales, lo cual genera paradójicas representaciones de otredad en las cuales convive la celebración del pasado de Al-Ándalus con la exaltación nacionalista del Cid, entre otras. Julio Ogas, por su parte, propone un enfoque hipertextual de la música de dos compositores de la posvanguardia argentina, Gerardo Gandini y Marta Lambertini, atendiendo a la relación de estas obras con composiciones precedentes y a la interpretación de esos usos en función del contexto cultural donde se generan. Para ello, recurre a la confluencia de las propuestas de Gerard Genette y Linda Hutcheon, con el fin de establecer ciertas coordenadas para un análisis textual que tenga en cuenta las diferentes formas en que esas músicas del pasado se introducen en la estructura de la obra y el uso discursivo que el compositor hace de ellas. 